\title{
Multiple Choices Options for Measuring Teaching Effectiveness
}

Research has validated the widespread belief that effective teaching matters, but what does effective teaching look like? And how can it be measured? There are a variety of methods for measuring teaching effectiveness. Some examine teachers' practices directly, whereas others emphasize student outcomes. Each method involves trade-offs, and no single method provides a complete picture of a teacher's effectiveness.

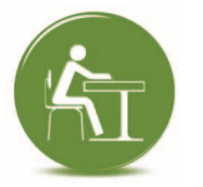

\section{Student test scores are one indicator of teaching effectiveness.}

Standardized tests provide an efficient way to measure how well students have learned basic content. For reading and math, teaching effectiveness can usually be estimated from standardized test scores using complex statistical methods, such as value-added modeling or student growth percentiles. When standardized test scores aren't available, other approaches can be used, such as student learning objectives (which assess teacher performance on the basis of specific student learning targets) or analysis of student work samples.

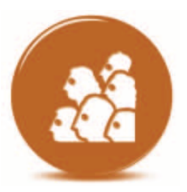

\section{Classroom observation measures teaching practices directly.}

The most commonly used method of measuring teaching practice is classroom observation. The observations can be done by principals, other teachers, or external evaluators, either in person or via video. Lesson plans and assignments can also be analyzed to learn more about a teacher's practices. All of these activities usually require more time and money than test-based estimates of teaching effectiveness.

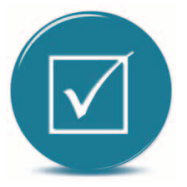

\section{Surveys and other methods can be informative.}

Growing numbers of districts and states use student surveys to gather feedback on student engagement and teacher-student relationships as another way to measure teaching effectiveness. Some districts also survey parents, particularly those of students who are too young to answer surveys. Teaching effectiveness can also be inferred from tests of teachers' knowledge or skills; from teachers' participation in professional development, committees, or mentoring; and from input provided by peers or administrators. However, these measures have not been as thoroughly examined by researchers as testbased or observation methods.

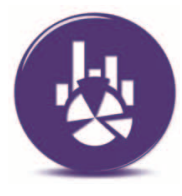

\section{Teaching is a complex activity that should be measured with multiple methods.}

Researchers have not yet identified the best way to combine information from multiple measures into an accurate overall rating of teaching effectiveness. The current state of the art is to use information from multiple measures to assess the many aspects of teaching effectiveness as completely as possible, providing teachers with detailed information to help them understand their strengths and weaknesses. 